\title{
EL TESTAMENTO DE RONALD DWORKIN: INDEPENDENCIA, UNIDAD Y VERDAD DEL VALOR, CON O SIN DIOS
}

\author{
Giuseppe Micciarelli
}

Università degli Studi Salerno

Nur ein Atheist kann ein guter Christ sein, nur ein Christ kann ein guter Atheist sein ERNST BLOCH

\section{¿Fe, religión o punto de vista?}

El último libro de Ronald Dworkin revela un objetivo fascinante: oponerse a la equivalencia -superficial y difundida al mismo tiempo- según la cual el ateísmo es sinónimo de falta de espiritualidad: en cambio, un ateo puede poseer convicciones profundas, caracterizadas por una tensión deberística imperativa similar a la de un creyente. A primera vista, este último libro se podría considerar atípico respecto del itinerario filosófico de uno de los más influyentes juristas del siglo XX. En este artículo quisiera afirmar, en cambio, que esta obra representa una pieza importante que se integra en la teoría jurídica del autor: el problema de la unidad, verdad e independencia del valor está inevitablemente relacionado con el de su fundamento.

Dworkin se niega a creer en un ser senciente e inteligente que ha proyectado el universo. Esto no le impide compartir un concepto de religiosidad que abarca "all deep convictions about the purpose and responsibilities of life". La religión -cuenta al principio del libro- "is deeper then God" y también los ateos pueden tener un "punto de vista religioso". Entonces, ¿a qué se refiere Dworkin cuando habla de religión y por qué 
su ateísmo necesita declararse religioso? ${ }^{1}$ Dos serían los aspectos que caracterizan este "punto de vista". En primer lugar, la convicción de que the "human life has objective meaning or importance" y que, por consiguiente, a cada individuo le compite la responsabilidad de llevar una "buena vida". En segundo lugar, la adhesión a una idea de la naturaleza empapada de esencia "numinosa", de una belleza inevitable, "not just a matter of fact but is itself sublime: something of intrinsic value and wonder". ${ }^{2}$ Estos dos fundamentos antinaturalistas constituirían el proprium de un sentimiento religioso fácil de compartir por teístas y por aquellos ateos, quienes -según la interpretación del autor de Espinoza y de Einstein- tenderían a una especie de panteísmo mecanicista. ¿Es realmente esta la esencia del concepto de religiosidad? A este respecto, tan innumerables son los estudios que, en este momento, no se pueden citar. Solo me limitaré a dar por sentada la perspectiva fundamental según la cual "una religión es una sistema solidario de creencias y de prácticas relativas a las cosas sagradas, es decir separadas, interdictas, creencias y prácticas que unen en una misma comunidad moral, llamada Iglesia, a todos aquellos que se adhieren a ellas". ${ }^{3}$ La articulación de la religión en un sistema complejo de prácticas, reglas, dogmas y ritualidades sedimentadas en el tiempo por medio de estudio y tradición es un aspecto que Dworkin parece subestimar, con tal de levantar inevitables críticas. ${ }^{4}$ Se podría objetar, pues, que la expresión "punto de vista religioso" usada en el libro pretende referirse más a un sencillo arranque interior de espiritualidad que a una auténtica fe. A esta altura se destaca un primer perfil crítico que concierne a la dimensión de creencia colectiva que adquiere la religión: ella vive si hay una comunidad, compuesta por creyentes, pero también por sus "sacerdotes" e intérpretes; una forma de iglesia es un elemento esencial de la espiritualidad religiosa ${ }^{5}$. Dworkin parece subvalorar este aspecto, revelando que su perspectiva corresponde a un punto de vista religioso esencialmente personal. La irrelevancia de Dios hace surgir disputas alrededor de las formas de religiosidad que hoy día se sustituyen a su ocaso, respaldadas

\footnotetext{
1. De esta manera, él diferencia su ateísmo tanto de las teorías clásicas de crítica a la religión de autores como Marx y Feuerbach como de los "naturalistas” contemporáneos como Richard Dawkins.

2. R. Dworkin, Religion without God, Harvard University Press, Cambridge (Mass.), 2013, p. 10.

3. E. Durkheim, Las formas elementales de la vida religiosa. El sistema totémico en Australia, Akal editor, Madrid, 1982, p. 42. 4. Cfr., por ejemplo, D. Zordan, "Religione e fede in Dworkin", en La società degli individui, 50, 2, 2014, pp.76-80. Véanse también las críticas del teólogo ibérico Manuel Fraijó, en cuyas páginas podría destacarse una crítica hacia planteamientos no diversos de los de Dworkin: "el idealista objetivo sobre todo es un esteta. No se siente "creyente", pero sí "religioso". Una religiosidad difundida, casi invisible, generosa, tolerante, sin dogmas vinculantes. Una religiosidad que se refleja perfectamente en las palabras de Goethe: búsquese el infinito, persigue el infinito en todas las direcciones”, M. Fraijó, “¿Religión sin Dios?", XXI Conferencias Aranguren, en "Isegoria, 47, 2, 2012, pp. 381-419. Cfr. también L.C. McClain, "Can Religion without God Lead to Religious Liberty without Conflict?”, http://www.bu.edu/bulawreview/symposium/a-symposium-on-ronald-dworkins-religion-without-god/.

5. Eso vale por las tres grandes religiones monoteístas que Dworkin considera, mientras que hay que destacar que, por lo que a las religiones sapienciales y a algunas de aquellas orientales se refiere, el tema es más complicado.
} 
por un siglo de descubrimientos científicos que han dado una explicación y un nombre a muchos de aquellos acontecimientos antes definidos "milagros". A pesar de eso, la manifiesta compartición de Dworkin de un punto de vista religioso tiene un fundamento objetivo: él también confía en un orden cósmico cuya belleza es "inevitable" y no casual. Para comprender la que le aparece como la espléndida simetría del universo, a religious atheist "must rely on physics and cosmology rather than theology".

Por supuesto, la obscuridad envuelve el misterio del principio y del final, que representan los polos extremos de la existencia y que, desde siempre, perturban los ánimos humanos $y$, pues, se debe admitir que alrededor de su inmensidad también el ateísmo de Dworkin parece haberse hecho derrotar por el deseo y la necesidad de dar al sentido del universo una respuesta "satisfactoria", término revelador que se repite a menudo a lo largo de las páginas del libro. Sin embargo, el sentimiento espiritual de Dworkin parece muy diferente del punto de vista completamente terrenal y antropocéntrico de aquel ateísmo que -siguiendo las huellas de Feuerbach- estigmatiza la mirada ultramundana como "agua de las lágrimas del corazón se evapora solo en el cielo de la fantasía, originando la formación nebulosa del ser divino. Del cósmico río Océano Homero se originan los dioses; pero esta corriente cargada de dioses en realidad solo es una efusión de los sentimientos humanos".

\section{El cierre del círculo interpretativo entre escatología y teoría del derecho}

Pues bien, si por algunos aspectos el punto de vista religioso de Dworkin parece criticable tanto por ateos como por creyentes, este adquiere un significado peculiar bajo su perspectiva filosófico-jurídica. El problema central con el cual relacionar la cuestión es el de la unidad e independencia de los valores morales y de su incorporación en el derecho por ser principios morales.

Bajo esta perspectiva, el problema que se plantea es el fundamento ético de la que Dworkin llama "society of principle": ella corre el riesgo de disgregarse cuando la comunidad política se halle caracterizada por sentimientos morales divergentes. En efecto,

6. R. Dworkin, Religion without God, p. 48.

7. Cfr. R. Dworkin, Law's Empire, The Belknap Press of Harvard University Press, Cambridge (Mass.), 1986, pp. 211 ss. Por lo que a este significado de comunidad de principio se refiere, cfr. V. Giordano, Il positivismo e la sfida dei principi, Esi, Napoli, 2004, pp. 171 ss.; A. Schiavello, Diritto come integrità: incubo o nobile sogno? Saggio su Ronald Dworkin, Giappichelli, Torino, 1997. 
los que parecen alejar más el uno del otro -por lo menos en el parcial y relativamente pacificado contexto de las democracias occidentales- son los "choques morales" entre laicos y creyentes. ${ }^{8}$ En sus escritos precendentes, Dworkin ha defendido siempre una concepción del derecho por la que "law includes not only the specific rules enacted in accordance with the community's accepted practices but also the principles that provide the best moral justification for those enacted rules"; 9 en Religion without God el esfuerzo dirigido a justificar una ética y una moral común que no esté caracterizada por el inagotable conflicto sobre la existencia de Dios llega a ser una pieza importante para mantener toda la arquitectura teórica del interpretativismo.

En efecto, la compartición de un "punto de vista religioso" también puede confluir en el necesario cumplimiento de una tarea: "what matters most fundamentally to the drive to live well is the conviction that there is, in dependently and objectively, a right way to live". ${ }^{10}$ Si todos los individuos, creyentes y no creyentes compartieran la responsabilidad individual de llevar una buena vida, indipendientemente de los contenidos que la determinan, la comunidad política poseería realmente un fundamento de principio común y estable. El estratagema para neutralizar un último conflicto sobre "lo verdadero" consiste en poner la aguja de la moralidad compartida al nivel de un deber colectivo en el que todo el mundo pueda reconocerse.

De esa manera, la perspectiva de un realismo valorial no fundacional y la teoría de "law as integrity" dworkiniana se armoniza con su visión religiosa: también the "religion is an interpretive concept". ${ }^{11}$ La técnica argumentativa -que, desde el punto de vista de los conflictos jurisprudenciales, puede llevar a la "right answer"- permite, al mismo tiempo, afirmar la verdad de los juicios de valor, a su vez insertados en un sistema general de valores. Como es sabido, en la última fase de su pensamiento, Dworkin intenta consolidar la teoría interpretativista a través de la confutación del hecho de que moral y derecho pertenecen a dos sistemas diversos e independientes. Total que llega a una afirmación en sentido fuerte de la verdad de los valores: también en los hard cases, el conflicto entre ellos -que emerge en el cotidiano contexto socio-político- solo sería ficticio: la justa solución interpretativa existe, aunque para alcanzarla sea necesario encomendarse a una estrategia argumentativa capaz de revelarla. Hay que detectar tales

\footnotetext{
8. Un conflicto, pues, que proporciona víctimas e injusticias no solo hacia los creyentes, tal como es posible leer en el último y dramático informe publicado en http://freethoughtreport.com/download-the-report/.

9. R. Dworkin, Justice for Hedgehogs, Harvard University Press, Cambridge (Mass.), 2013, p. .388.

10. R. Dworkin, Religion without God, p. 155.

11. Ibid., p. 7.
} 
razones en el interior del mismo discurso moral, no siendo necesario servirse de auxilios externos de tipo físico, antropológico, estadístico, etc.

En resumidas cuentas, Dworkin acentúa el problema de la verdad: un desafío que, sin el auxilio de la fe, ya al principio podría parecer derrotado, sobre todo hoy día. En un mundo globalizado, fragmentado en identidades, culturas y opiniones políticas, el razonamiento alrededor de lo verdadero podría parecer no solo fuera de lugar sino -peor aún peligroso. Por supuesto, Dworkin es plenamente consciente del alcance del problema que expone, pero creo que lo empuja una convicción profunda: si renunciáramos a creer en la verdad, pues, también renunciaríamos al esfuerzo de explicar nuestras convicciones morales, que es el único modo de enfrentamiento pacífico posible sobre esos temas. Para aspirar a la credibilidad, tales razones deben concentrarse en la verdad: la verdad debe quedar en el horizonte de lo posible, de otra manera no tendría sentido ni siquiera discutir de ella. ${ }^{12}$ Podríamos decir, pues, que el riesgo de una verdad no alcanzable equivale al menosprecio de las convicciones morales que orientan a los individuos en aquel recorrido espiritual y ético que solo la presunción de la verdad puede poner en marcha.

A esa altura, pues, el ateísmo religioso acaba convirtiéndose en una necesidad: la posibilidad de la verdad debe sobrevivir también sin un Dios que la determine y la revele, sin medios de comprobación que verifiquen la validez, desde el exterior, de su significado; para sobrevivir incluso sin estos instrumentos se necesita de una fe inquebrantable hacia el sentido de la vida y la obligación de llevarla de una determinada forma. Hay por lo menos dos críticas que se pueden dirigir a esta noble tentativa.

El primer punto crítico atañe al roce que se da entre la independencia del individuo y la colectividad, un momento que compromete directamente la dimensión histórica -y, pues, al menos diacrónicamente relativa- de los valores morales. Pues, en este caso, las críticas que se pueden imputar a la visión religiosa de Dworkin son especulares a las que se pueden dirigir a su teoría jurídica: por mucho que las corrientes jusnaturalistas o antipositivistas quieran modernizarse, el problema es que ellas "se basan en una pretensión de autoevidencia de los principios a la que le resulta difícil conciliarse con la transformación histórica y tout court con la experiencia”. ${ }^{13}$

A esta altura, Dworkin propone una de las meditaciones más importantes de la obra, suponiendo la reinterpretación de los derechos de libertad religiosa no a través del

12. Cfr. sobre todo R. Dworkin, Justice for Hedgehogs, pp. 402 ss.

13. A. Catania, Diritto naturale e diritto positivo, en A. Catania, L. Lombardi Vallauri (eds.), Concezioni del diritto e confronti Oriente-Occidente, Esi, Napoli, 2000, p. 102. 
esquema interpretativo de un derecho especial, sino por medio del de un derecho más general to ethical independence. El perfil problemático se puede entrever en el pasaje en el que el reconocimiento de similar independencia, planteada como originaria en la esfera del individuo, entra en/choca con aquella ineludible dimensión colectiva que la espiritualidad adquiere cuando se concibe como religión. Las posibilidades y las dudas proporcionadas por el progreso científico en relación con la bioética, las cuestiones que atañen a la libertad de enseñanza, el aborto, la eutanasia, la pornografía y la moral sexual $^{14}$ representan temas difíciles desde el punto de vista moral, por lo menos por dos motivos que vuelven la cuestión aún más compleja: en primer lugar, atañen a sujetos incapaces o a los que la conciencia civil considera necesario proteger siendo débiles en sentido lato; en segundo lugar, porque la disciplina legislativa en materia no influye solo en la independencia del individuo, sino también compromete a toda la colectividad, proporcionando la imagen que una comunidad - a fortiori si se concibe "de principio"da a ella misma. Justo en esas ocasiones, pues, la "best conception of constitutional moral principles", con relación a los casos concretos y a la evolución histórica, a menudo produce conflicto antes que cohesión colectiva.

El segundo punto crítico se refiere a la posibilidad de que la moral y otros ámbitos del valor se puedan hallar de por sí, por ser filosóficamente independientes. En cambio, desde una perspectiva diferente, el juicio moral se debe considerar como interior a una forma de ejercicio del poder. Tal como demuestran los estudios de Michel Foucault sobre la sexualidad y la confesión, las técnicas de poder no se limitan a reprimir y prohibir, prescribiendo los comportamientos por medio de la dicotomía legal lícito/ilícito; el poder se ejerce también por medio de la definición de ámbitos de saberes y de regímenes de verdades que se manifiestan en el sentido de la moral y en el pecado. Hasta se puede compartir la idea según la cual algunos preceptos morales nacen como "irreflejos", es decir, como connaturales al hombre ${ }^{15}$, pero solo si consideramos aquellos pocos instantes primarios dirigidos a la conservación de la especie. Otras atribuciones de tipo moral amenazan otorgar a lo humano una naturaleza a imagen y semejanza de los contemporáneos del momento.

Este último punto me permite hallar en la 'ilustración' de Dworkin no solo un evidente recuerdo kantiano, sino también resonancias del mito del buen salvaje roussoviano y, sobre todo, del pensamiento de Voltaire. Claro está, la intención de Dworkin no es la de fundar una religión civil pero, a pesar de eso, el razonamiento que propone podría

14. Se trata, pues, de problemas ampliamente analizados por Dworkin, también en breves ensayos: R. Dworkin, “The Court \& Abortion: Worse than you Think", in N.Y. Rev. Books, 31 May, 2007, , R. Dworkin et al., "Assisted Suicide: The Philosopher's Brief”, in N.Y. Rev. Books, 27 March., 1997, R. Dworkin, “Liberty and Pornography”, in N.Y. Rev. Books, 15 Aug., 1991. 15. Cfr. R. Dworkin, Justice for Hedgehogs, pp. 102 ss. 
recordar las páginas del padre de la Encyclopédie acerca del culto de la diosa razón. Tal vez no sea una coincidencia que el título de Dworkin es el mismo que el elegido por William Arthur en 1885 para reflexionar alrededor de los progresos del catecismo positivista de Comte de influencia deísta. ${ }^{16}$

En conclusión, tal vez el relativismo del zorro -aún más en un ámbito tan delicado como el de la fe religiosa- no sea un gesto de astucia, ni tampoco una renuncia a la búsqueda de la verdad; de lo contrario, es la tentativa extrema de intentar prohibir el hecho de que alguien la declare adquirida, revelada y encarnada en una u otra convicción moral. La verdad revelada o, también moderadamente interpretada, es árida respecto del relativismo pero, por lo menos, es más difícil que llame a las armas a sus irreducibles partidarios.

Traducción del italiano de M. Colucciello

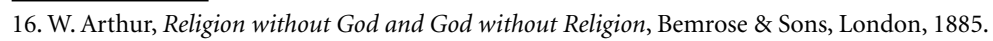

